\title{
Evidence of Multiple Virulence Subtypes in Nosocomial and Community-Associated MRSA Genotypes in Companion Animals from the Upper Midwestern and Northeastern United States
}

\author{
Yihan Lin, BS; Emily Barker; Jennifer Kislow, BS; Pravin Kaldhone, MS; Mary E. Stemper, MS; \\ Madhulatha Pantrangi, PhD; Frances M. Moore, DVM; Matthew Hall, MD; Thomas R. Fritsche, MD; \\ Thomas Novicki, PhD; Steven L. Foley, PhD; and Sanjay K. Shukla, PhD
}

\begin{abstract}
Objective: Not much is known about the zoonotic transmission of methicillin-resistant Staphylococcus aureus (MRSA) in companion animals in the United States. We report the rate of prevalence of S. aureus and MRSA recovered from clinical samples of animals requiring treatment at veterinary clinics throughout the upper midwestern and northeastern United States.
\end{abstract}

Design: We compared phenotypes, genotypes, and virulence profiles of the MRSA isolates identified in companion animals, such as cats, dogs, horses, and pigs, with typical human nosocomial and community-associated MRSA (CA-MRSA) genotypes to assess implied zoonotic transmission or zooanthroponosis. Five hundred thirty-three coagulase-positive staphylococci (CPS) isolates recovered between 2006 and 2008 from a variety of animal-source samples were screened for S. aureus by S. aureus-specific $16 \mathrm{~S}$ rDNA primers and were screened for methicillin-resistance. All MRSA isolates were genotyped by pulsed-field gel electrophoresis (PFGE), multilocus sequence typing (MLST), and spa typing. They were also screened for common staphylococcal enterotoxin and adhesion genes by multiplex and singleplex PCR.

Results: Among the 533 CPS isolates recovered, 66 (12.4\%) were determined to be S. aureus and 24 (4.5\%) were MRSA. The percent of animals that were positive for S. aureus were as follows: $6.6 \%$ (32 of 487 ) dogs, $39.6 \%$ ( 19 of 48 ) cats, $83.3 \%$ (I0 of I2) horses, and I00\% of pigs, rabbits, hamsters and rats. Notably, $36.4 \%$ of all S. aureus identified were MRSA. Methicillin-resistant S. aureus was present in clinical samples from 12 of 487 dogs (2.5\%), 6 of 48 cats (I2.5\%), 5 of I 2 horses (42\%), and I of 2 pigs (50\%). The 24 MRSA isolates resolved into 4 PFGE clones: USAI00 (50\%), USA300 (16.7\%), USA500 (20.8\%) and USA800 (I2.5\%) and 6 sequence types (ST5, ST8, ST 105, ST830, and ST986) or 2 clonal complexes, CC5 and CC8. Five major virulence profiles (clusters A to E) were observed in these MRSA isolates. Genotypic and virulence profiles of cats and dogs were more similar to each other than to those of horses. A Panton-Valentine leukocidin positive isolate with ST8:USA300 background was identified in a pig causing skin and soft infection.

Conclusion: The presence of human MRSA clones in these animals suggests possible reverse zoonotic transmission. This study reports the first case of a USA300 genotype in a pig. Presence of multiple virulence profiles within a MRSA genotype in these animals suggests the potential of emergence of new MRSA clones by gaining or losing additional virulence genes.

Keywords: CA-MRSA; MRSA; Nosocomial; Staphylococcus aureus; Virulence; Zoonotic

Corresponding Author: Sanjay K. Shukla, PhD, Molecular Microbiology Laboratory, Marshfield Clinic Research Foundation, 1000 North Oak Avenue, Marshfield, WI 54449, Tel: 7/5-389-5363, Fax: 7/5-389-5757.

Email: shukla.sanjay@mcrf.mfldclin.edu
Received: June 4, 2010

Revised: August 3, 2010

Accepted: August 4, 2010

doi: $10.3121 / \mathrm{cmr} .2010 .944$ 
$S$ capable of producing a wide range of diseases from skin and soft tissue infections to life-threatening endocarditis, bacteremia, and necrotizing pneumonia. ${ }^{1}$ Infections due to $S$. aureus have assumed new public health importance due to emerging multiple antibiotic resistant strains, particularly methicillin-resistant $S$. aureus (MRSA) and its epidemic clones increasingly being found in communities and hospitals. $^{2,3}$ Typically, community-associated MRSA genotypes belong to USA300, USA400, USA1000, and USA1100, whereas healthcare-associated MRSA genotypes belong to USA100, USA200, and USA500. ${ }^{4,5}$

While MRSA has long been recognized in human healthcare settings and in people in the community without known risk factors, its ability to produce disease in domesticated companion and farm animals (eg, dogs, cats, horses, and pigs) has gained attention in recent years. The first case of MRSA reported in an animal setting was in 1972 from Belgian dairy cows with mastitis. ${ }^{6}$ Since that time, reports have documented cases of MRSA in dogs, cats, horses, pigs, and other animal species. ${ }^{7-15}$ Except for ST398, the majority of MRSA isolated from these animals have been human MRSA clones known to circulate in hospital settings, ${ }^{11,14-20}$ leading to the speculation that MRSA could be transmitted from humans to animals. Most of these reports of zoonotic MRSA have come from Europe, Asia, and Canada. ${ }^{15,21-25}$ There are few reports describing the prevalence of MRSA recovered from animals in the United States. ${ }^{26-28}$ The aim of this study was to determine the frequency, genotypic characteristics, and virulence attributes of MRSA recovered from animal samples submitted to a regional veterinary diagnostic reference laboratory. These clinical samples were submitted from animals requiring treatment located in the midwestern and northeastern regions of the United States.

\section{Methods}

Collection of Study Isolates

Five-hundred thirty-three isolates of coagulase positive staphylococci (CPS) were recovered from companion animals that were treated at numerous veterinary clinics located throughout the midwestern and northeastern United States (Michigan, Minnesota, New Hampshire, Ohio, Pennsylvania, Wisconsin). Clinical specimens were submitted to Marshfield Labs, a diagnostic laboratory of Marshfield Clinic (Marshfield, Wisconsin) from March 2006 to October 2008 for routine culture and sensitivity testing. All CPS isolates collected during that time period were included in this study.

\section{Microbial Susceptibility Testing}

Microbial susceptibilities were performed using the diskdiffusion method according to the Clinical Laboratory Standards Institute guidelines. ${ }^{29}$ Antimicrobials tested included ampicillin, enrofloxacin, cephalothin, neomycin, amoxicillin/clavulanic acid, erythromycin, gentamicin, marbofloxacin, orbifloxacin, oxacillin, trimethoprim/ sulfamethoxazole, and tetracycline.

\section{Identification of S. aureus}

All study isolates were identified as being $S$. aureus using a $S$. aureus-specific $16 \mathrm{~S}$ rDNA polymerase chain reaction (PCR) assay developed in our laboratory. Forward and reverse primers were

StaA-F 5'-GACGAGAAGCTTGCTTCTCTGATG-3' and StaA-R2 5'-TAATGCAGCGCGGATCCA-3', respectively. Polymerase chain reaction assay conditions have been described previously. ${ }^{30}$

\section{mecA Screening}

Isolates that were identified as $S$. aureus and were oxacillin resistant based on antimicrobial susceptibility testing were further confirmed using mecA PCR as previously described. $^{31}$

\section{Molecular Typing}

All MRSA isolates were genotyped by pulsed-field gel electrophoresis (PFGE), multilocus sequence typing (MLST), and staphylococcal protein A ( $s p a$ ) typing using protocols previously described. ${ }^{32-34}$ The PFGE-based dendrogram was created using the Dice coefficient and the unweighted-pair group method using arithmetic averages. Clones were defined using $80 \%$ genetic similarity and $1.25 \%$ tolerance by PFGE in combination with the staphylococcal cassette chromosome mec (SCCmec) and MLST typing data. Staphylococcal cassette chromosome mec types were determined using the method of Oliviera and de Lencastre. ${ }^{35}$ Multilocus sequence typingbased sequence types (ST) were clustered into clonal complexes (CCs) using eBURST analysis (http://eburst.mlst.net/). A CC was defined as having six out of seven identical loci of the MLST allelic profile. Using the Based Upon Repeat Pattern (BURP) algorithm within Ridom Staphtype software (http:// www3.ridom.de/spa-server/; version 1.5.17; Ridom GmbH, Wurzburg, Germany), spa types were also grouped into spa clonal complexes $(\operatorname{spaCC})$. Default parameters $(\mathrm{x}=5 ; \mathrm{y}=4)$ were applied. ${ }^{36}$ BURP analysis allows determination of clonal relatedness based on spa types of $S$. aureus.

\section{Virulence Gene Profile PCR Assay}

Methicillin-resistant $S$. aureus isolates were screened by a combination of multiplex and singleplex PCR for several virulence genes which included staphylococcal enterotoxins (sea, seb, sec, sed, see, seg, seh, sei, sej, sek, sel, sem, sen, $s e o$ ), Panton-Valentine Leukocidin (lukSF-PV), and staphylococcal adhesions ( $f n b A, f n b B, c l f A$, and $c l f B$ ). The list of primers and PCR methods has been described previously. ${ }^{37}$ The PCR results were analyzed as binary data using Dice coefficients and maximum parsimony tree analysis (BioNumerics, Applied-Maths, Kortrijk, Belgium).

\section{Results}

The distribution of clinical specimens from animals found to be positive for CPS $(n=533)$ included dogs $(n=487)$, cats 
Table 1. Number of animals screened along with the rate of positivity for S. aureus and MRSA.

\begin{tabular}{|c|c|c|c|c|}
\hline Animal & $\begin{array}{l}\text { CPS-positive } \\
\text { (n) }\end{array}$ & $\begin{array}{l}\text { S. aureus } \\
\text { n (\%) }\end{array}$ & $\begin{array}{c}\text { MRSA-positive } \\
\text { S. aureus } \\
\text { n (\%) }\end{array}$ & $\begin{array}{c}\text { MRSA-positive } \\
\text { CPS (\%) }\end{array}$ \\
\hline Dog & 487 & $32(6.6)$ & $12(37)$ & 2.5 \\
\hline Cat & 48 & 19 (39.6) & $6(32)$ & 12.5 \\
\hline Horse & 12 & 10 (83.3) & $5(50)$ & 42 \\
\hline Pig & 2 & $2(100)$ & $1(50)$ & 50 \\
\hline Rabbit & 1 & 1 (100) & $0(0)$ & 0 \\
\hline Hamster & 1 & $1(100)$ & $0(0)$ & 0 \\
\hline Rat & 1 & $1(100)$ & $0(0)$ & 0 \\
\hline Total & 533 & 66 (12) & $24(36.4)$ & 5 \\
\hline
\end{tabular}

$(n=48)$, horses $(n=12)$, pigs $(n=2)$, hamster $(n=1)$, rabbit $(n=1)$, mink $(n=1)$, and rat $(n=1)$ (table 1$)$. Sixty-six of the CPS isolates (12.4\%) were identified as $S$. aureus by the $S$. aureus-specific PCR. The number and percent of animals that were positive for $S$. aureus were as follows: 32 of $487(6.6 \%)$ dogs, 19 of $48(40 \%)$ cats, 10 of $12(83 \%)$ horses, and $100 \%$ of pigs, rabbits, hamsters and rats. Twenty-four of these 66 (36.4\%) S. aureus isolates were confirmed to be mecA PCR positive. These MRSA isolates originated from samples obtained from dogs $(n=12)$, cats $(n=6)$, horses $(n=5)$, and pig $(\mathrm{n}=1)$. The percent of $S$. aureus in each animal that were MRSA were $\operatorname{dog}_{s} 37 \%$, cats $32 \%$, horses $50 \%$, and pigs $50 \%$. However, the percent of CPS that were found to be MRSA in horses, cats, and dogs were $42 \%, 12 \%$, and $2 \%$ respectively. The month and year of isolation of the MRSA, state from which samples were received, and source of the clinical samples was documented (table 2).

Most of the samples represented skin/soft tissue infections or abscesses. As expected, all mecA positive isolates were phenotypically resistant to oxacillin $(\geq 4 \mu \mathrm{g} / \mathrm{ml})$. Most isolates were susceptible to trimethoprim/sulfamethoxazole $(83 \%)$, tetracycline (75\%), and gentamicin (71\%), and were less susceptible to erythromycin (29\%), marbofloxacin (29\%), enrofloxacin (30\%), orbifloxacin (31\%), and neomycin (37\%) (table 3). Interestingly, unlike MRSA isolates from dogs and cats, most MRSA isolates from horses were resistant to trimethoprim/sulfamethoxazole and tetracycline but were susceptible to enrofloxacin and erythromycin.

Table 2. List of MRSA isolates, their animal sources, date of isolation, origin of state and clinical source for each specimen.

\begin{tabular}{|c|c|c|c|c|}
\hline Isolate \# & Species & Isolate Date & Origin & Source \\
\hline V-385 & Canine & $11 / 2006$ & $\mathrm{OH}$ & Skin \\
\hline V-394 & Canine & $12 / 2006$ & PA & Skin \\
\hline$V-164$ & Canine & $5 / 2006$ & WI & Wound \\
\hline$V-536$ & Canine & $2 / 2008$ & PA & Catheter \\
\hline$V-563$ & Feline & $3 / 2008$ & $\mathrm{OH}$ & Leg \\
\hline V-607 & Canine & $4 / 2008$ & PA & Implant \\
\hline V-379 & Feline & $2 / 2007$ & $\mathrm{OH}$ & Arm \\
\hline V-031 & Canine & $3 / 2006$ & MN & Bone \\
\hline$V-411$ & Canine & $1 / 2007$ & $\mathrm{NH}$ & Biopsy \\
\hline$V-223$ & Canine & $9 / 2006$ & MN & Other \\
\hline V-381 & Canine & $11 / 2006$ & MN & Thigh \\
\hline$V-501$ & Feline & $6 / 2007$ & $\mathrm{Ml}$ & Tissue \\
\hline$V-516$ & Feline & $2 / 2008$ & $\mathrm{Ml}$ & Tissue \\
\hline V-272 & Canine & $12 / 2006$ & PA & Skin \\
\hline$V-450$ & Feline & $1 / 2008$ & MN & Lesion \\
\hline$V-522$ & Pig & $2 / 2008$ & WI & Abscess \\
\hline$V-569$ & Canine & $3 / 2008$ & MN & Paw \\
\hline$V-453$ & Feline & $6 / 2007$ & MN & Lesion \\
\hline V-046 & Equine & $4 / 2006$ & PA & Heel \\
\hline$V-446$ & Equine & $5 / 2007$ & WI & Discharge from incision \\
\hline$V-519$ & Equine & $2 / 2008$ & WI & Draining tract \\
\hline$V-526$ & Equine & $2 / 2008$ & WI & Draining tract \\
\hline V-708 & Equine & $8 / 2008$ & MN & Draining tract \\
\hline$V-744$ & Canine & $10 / 2008$ & $\mathrm{OH}$ & Abscess \\
\hline
\end{tabular}


Table3. Antimicrobial susceptibility profile of the MRSA isolates.

\begin{tabular}{|c|c|c|c|c|c|c|c|c|c|c|c|c|c|c|}
\hline Isolate \# & Source & MLST & $\sum_{<}^{0}$ & 㐫 & 㞻 & $\begin{array}{l}\text { 음 } \\
\text { Z }\end{array}$ & $\frac{4}{0}$ & 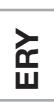 & 离 & $\underset{\mathbf{L}}{\mathbf{\alpha}}$ & 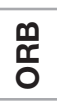 & \̊ & 攴 & $\underset{⺊}{\mathfrak{b}}$ \\
\hline V-031 & Canine & ST5 & $\mathrm{R}$ & $\mathrm{R}$ & $\mathrm{R}$ & $\mathrm{R}$ & $\mathrm{R}$ & $\mathrm{R}$ & $S$ & $\mathrm{R}$ & $\mathrm{R}$ & $\mathrm{R}$ & $S$ & $S$ \\
\hline V-046 & Equine & ST8 & $\mathrm{R}$ & $S$ & $\mathrm{R}$ & $S$ & $\mathrm{R}$ & $\mathrm{R}$ & $S$ & $S$ & $S$ & $\mathrm{R}$ & $\mathrm{R}$ & $\mathrm{R}$ \\
\hline V-164 & Canine & ST5 & $\mathrm{R}$ & $\mathrm{R}$ & $\mathrm{R}$ & $\mathrm{R}$ & $\mathrm{R}$ & $\mathrm{R}$ & $S$ & $\mathrm{R}$ & $\mathrm{R}$ & $\mathrm{R}$ & $S$ & $S$ \\
\hline V-223 & Canine & ST5 & $\mathrm{R}$ & $\mathrm{R}$ & $\mathrm{R}$ & $\mathrm{R}$ & $\mathrm{R}$ & $\mathrm{R}$ & $S$ & $\mathrm{R}$ & $\mathrm{R}$ & $\mathrm{R}$ & $S$ & $S$ \\
\hline V-272 & Canine & ST986 & $\mathrm{R}$ & $S$ & $\mathrm{R}$ & $S$ & $\mathrm{R}$ & $S$ & $\mathrm{R}$ & $S$ & $S$ & $\mathrm{R}$ & $S$ & $S$ \\
\hline V-379 & Feline & ST5 & $\mathrm{R}$ & $\mathrm{R}$ & $\mathrm{R}$ & $\mathrm{R}$ & $\mathrm{R}$ & $\mathrm{R}$ & $S$ & $\mathrm{R}$ & $\mathrm{R}$ & $\mathrm{R}$ & $S$ & $S$ \\
\hline V-381 & Canine & ST5 & $\mathrm{R}$ & $\mathrm{R}$ & $\mathrm{R}$ & $\mathrm{R}$ & $\mathrm{R}$ & $\mathrm{R}$ & $S$ & $\mathrm{R}$ & $\mathrm{R}$ & $\mathrm{R}$ & $S$ & $S$ \\
\hline V-385 & Canine & ST105 & $\mathrm{R}$ & $\mathrm{R}$ & $\mathrm{R}$ & $\mathrm{R}$ & $\mathrm{R}$ & $\mathrm{R}$ & $S$ & $\mathrm{R}$ & $\mathrm{R}$ & $\mathrm{R}$ & $S$ & $S$ \\
\hline V-394 & Canine & ST105 & $\mathrm{R}$ & $\mathrm{R}$ & $\mathrm{R}$ & $\mathrm{R}$ & $\mathrm{R}$ & $\mathrm{R}$ & $\mathrm{R}$ & $\mathrm{R}$ & $\mathrm{R}$ & $\mathrm{R}$ & $S$ & $S$ \\
\hline V-411 & Canine & ST5 & $\mathrm{R}$ & $\mathrm{R}$ & $\mathrm{R}$ & $\mathrm{R}$ & $\mathrm{R}$ & $\mathrm{R}$ & $\mathrm{R}$ & $\mathrm{R}$ & $\mathrm{R}$ & $\mathrm{R}$ & $S$ & $S$ \\
\hline V-446 & Equine & ST8 & $\mathrm{R}$ & $S$ & - & - & - & $S$ & $\mathrm{R}$ & - & - & $\mathrm{R}$ & $\mathrm{R}$ & $\mathrm{R}$ \\
\hline$V-450$ & Feline & ST8 & $\mathrm{R}$ & $\mathrm{R}$ & $\mathrm{R}$ & - & $\mathrm{R}$ & $\mathrm{R}$ & $S$ & - & - & $\mathrm{R}$ & $S$ & $S$ \\
\hline V-453 & Feline & ST8 & $\mathrm{R}$ & $\mathrm{R}$ & $\mathrm{R}$ & - & $\mathrm{R}$ & $\mathrm{R}$ & $S$ & - & - & $\mathrm{R}$ & $S$ & $S$ \\
\hline V-501 & Feline & ST5 & $\mathrm{R}$ & $S$ & $\mathrm{R}$ & $S$ & $\mathrm{R}$ & $S$ & $S$ & $S$ & $S$ & $\mathrm{R}$ & $S$ & $S$ \\
\hline V-516 & Feline & ST5 & $\mathrm{R}$ & $S$ & $\mathrm{R}$ & $S$ & $\mathrm{R}$ & $S$ & $S$ & $S$ & $S$ & $\mathrm{R}$ & $S$ & $S$ \\
\hline V-519 & Equine & ST8 & $\mathrm{R}$ & $S$ & - & - & $S$ & $S$ & $\mathrm{R}$ & - & - & $\mathrm{R}$ & $\mathrm{R}$ & $\mathrm{R}$ \\
\hline V-522 & Pig & ST8 & $\mathrm{R}$ & $\mathrm{R}$ & $\mathrm{R}$ & - & $\mathrm{R}$ & $\mathrm{R}$ & $S$ & - & - & $\mathrm{R}$ & $S$ & $\mathrm{~S}$ \\
\hline V-526 & Equine & ST8 & $\mathrm{R}$ & $S$ & - & - & $S$ & $S$ & $\mathrm{R}$ & - & - & $\mathrm{R}$ & $\mathrm{R}$ & $\mathrm{R}$ \\
\hline V-536 & Canine & ST5 & $\mathrm{R}$ & $\mathrm{R}$ & $\mathrm{R}$ & $S$ & $\mathrm{R}$ & $\mathrm{R}$ & $S$ & $\mathrm{R}$ & $\mathrm{R}$ & $\mathrm{R}$ & $S$ & $S$ \\
\hline V-563 & Feline & ST5 & $\mathrm{R}$ & I & $\mathrm{R}$ & $S$ & $\mathrm{R}$ & $\mathrm{R}$ & $S$ & $S$ & $S$ & $\mathrm{R}$ & $S$ & $S$ \\
\hline V-569 & Canine & ST8 & $\mathrm{R}$ & - & $\mathrm{R}$ & - & $\mathrm{R}$ & $\mathrm{R}$ & $S$ & $\mathrm{R}$ & - & $\mathrm{R}$ & $S$ & $\mathrm{R}$ \\
\hline V-607 & Canine & ST5 & $\mathrm{R}$ & $\mathrm{R}$ & $\mathrm{R}$ & I & $\mathrm{R}$ & $\mathrm{R}$ & $S$ & $\mathrm{R}$ & $\mathrm{R}$ & $\mathrm{R}$ & $S$ & $S$ \\
\hline V-708 & Equine & ST830 & $\mathrm{R}$ & I & $\mathrm{R}$ & - & $\mathrm{R}$ & $S$ & $\mathrm{R}$ & - & - & $\mathrm{R}$ & - & $\mathrm{R}$ \\
\hline V-744 & Canine & ST5 & $\mathrm{R}$ & $\mathrm{R}$ & $\mathrm{R}$ & $\mathrm{R}$ & $\mathrm{R}$ & $\mathrm{R}$ & $S$ & $\mathrm{R}$ & $\mathrm{R}$ & $\mathrm{R}$ & $S$ & $S$ \\
\hline
\end{tabular}

MLST, multilocus sequence typing; AMP, Ampicillin; BAY, enrofloxacin; CEP; Cephalothin; NEO, Neomycin;

CLA, Amoxicillin/Clavulanic acid; ERY, Erythromycin; GEN, Gentamicin; MAR, Marbofloxacin; ORB, Orbifloxacin;

OXA, Oxacillin; SXT, Trimethoprim/Sulfamethoxazole; TET, Tetracycline; - = not determined

\section{Genotypes of MRSA Identified}

Genotypic data were analyzed in the context of CDC- (Center for Disease Control and Prevention, USA) defined USAgenotypes, MLST-based STs and CCs, and spa types and spaCCs. Four PFGE types, USA100, USA300, USA500, and USA800, were identified from the 24 MRSA isolates (figure 1). USA100 was the predominant clone, represented by 12 isolates, 10 of which originated from dogs and 2 from cats. All USA100 isolates belonged to CC5: ST5 or ST105 and SCCmec type II. Four spa types were observed with t002 being predominant $(78 \%)$ and one representation of $\mathrm{t} 242$, t442, and 045 each in CC5 (figure 1). The three USA800 strains represented by ST5 and ST986 and SCCmec type IVa came from two cats and one dog. The two cat isolates were of spa type t688, whereas the dog isolate belonged to spa t002. Four USA300 isolates belonging to CC8 (ST8, SCCmec type IV) with spa type t008 were identified. Two of these isolates came from cats and one each from a dog and a pig. All five USA500 isolates also belonged to CC8 and came from horses. Four of the five horse isolates were of spa type t064.

Overall, $62.5 \%$ of the MRSA isolates belonged to CC5, whereas $37.5 \%$ belonged to CC8. Staphylococcal cassette chromosome mec types II and IV were primarily associated with ST5 and ST8 respectively, with some exceptions. Of the nine spa types identified (figure 1), type t002 was the most common $(\mathrm{n}=8)$ and was mainly associated with dog isolates
(7 of 8). BURP analysis of the nine spa types revealed two spaCC and two singletons. The spaCC t002 consisted of spa types t002, t045, t242, and t548, with $\mathrm{t} 002$ as its founder (figure 2). The other spaCC consisted of types t008 and t064 with no identified founder. The two spa types identified as singletons were $\mathrm{t} 190$ and $\mathrm{t} 688$.

\section{Distribution of Virulence Genes}

Five virulence genes clusters (A to E) were seen in the 24 MRSA isolates tested (figure 3A). All MRSA isolates were positive for genes encoding clumping factors $\mathrm{A}$ and $\mathrm{B}$ ( clfA and $c l f B$ ), and all but one were positive for a fibrinogen binding protein gene, $f n b A$. Isolates in the $\mathrm{CC} 5$ showed two major virulence genes clusters, A and $\mathrm{B}$, whereas $\mathrm{CC} 8$ displayed three clusters, $\mathrm{C}, \mathrm{D}$, and $\mathrm{E}$. Only isolates in cluster D (CC8, ST8:SCCmec IVa) harbored Panton-Valentine leukocidin (PVL), a known tissue necrosis factor and one of the major virulence genes in CA-MRSA. Isolates belonging to CC5 were predominantly positive for an enterotoxin gene cluster $(e g c), s e g$, sei, sem, sen, seo, and sej, but were negative for seb, see, seh, sek, and sel. Enterotoxin genes sea, seb, sec, and sed, and $f n b B$ were inconsistently present in $\mathrm{CC} 5$ isolates. Of the three clusters in $\mathrm{CC} 8$, cluster $\mathrm{C}$ was represented by a single equine isolate, $\mathrm{V} 046$, and harbored enterotoxin genes $s e b$, sek and egc in addition to $c l f A, c l f B, f n b A$ and $f n b B$. The cluster $\mathrm{D}$ isolates differed from cluster $\mathrm{C}$ due to absence of $f n b B$, seb, and egc but the presence of lukSF-PV. One 


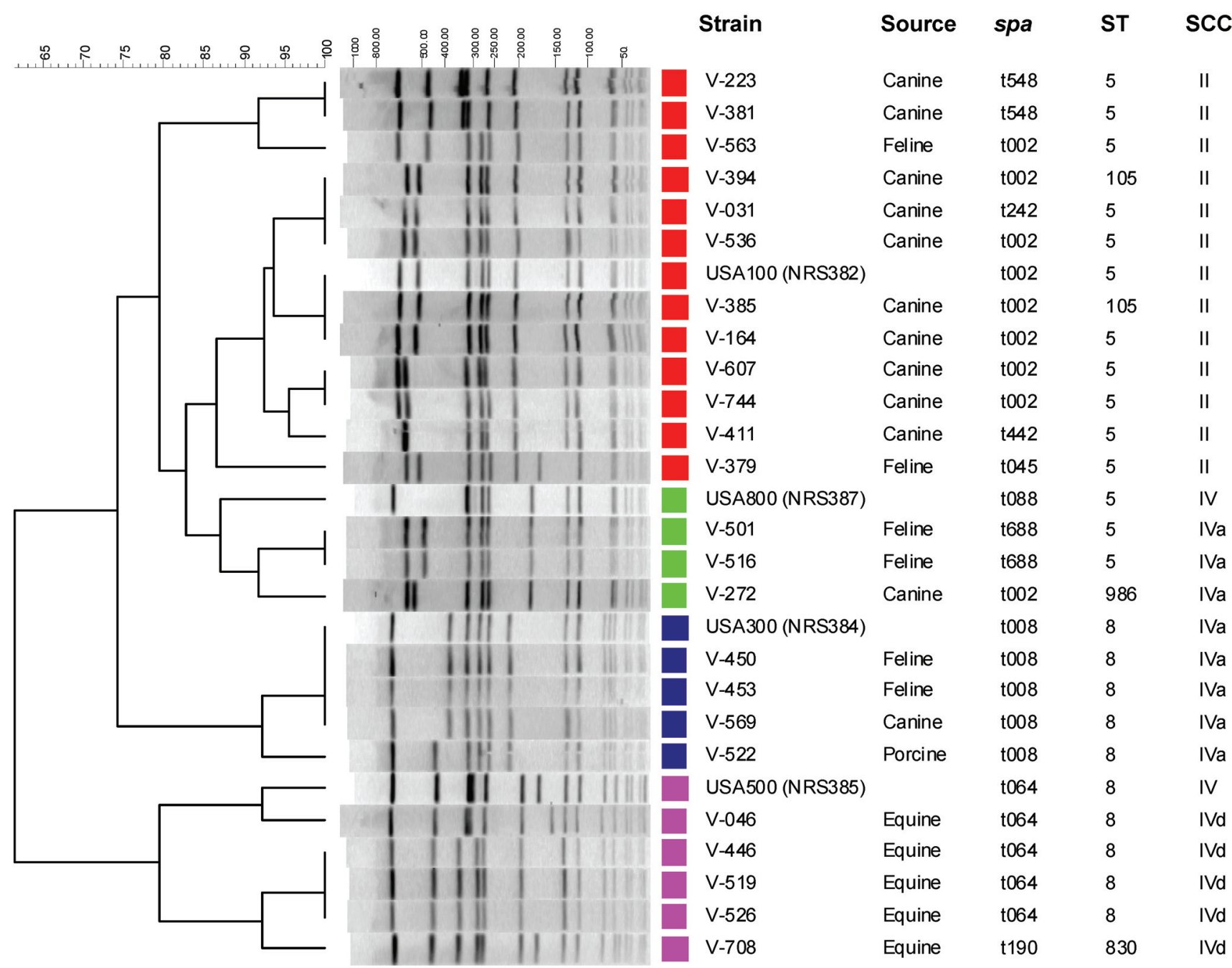

Figure 1. Pulsed-field gel electrophoresis-based dendrogram of the 24 methicillin-resistant Staphylococcus aureus isolates identified in this study. The dendrogram was created using the Dice coefficient and the unweighted-pair group method using arithmetic averages. Clonal relatedness was determined by $80 \%$ genetic similarity and $1.25 \%$ tolerance.

Panton-Valentine leukocidin positive isolate causing skin and soft tissue infection (ST8:USA300) was identified in a pig. The cluster E isolates, on the other hand, harbored seb but not lukSF-PV in conjunction with clfA, clfB, fnbA, and sek, with the exception of isolate $\mathrm{V}-078$ which had gained the sea gene. All CC8 isolates contained sek, unlike CC5 isolates. Conversely, all CC5 isolates had sem and sen, while none of the CC8 isolates did (figure 3A). The virulence profile of isolate V-046, a CC8 isolate, was unique in that it had three of the egc (seg, sei, sej) found only in CC5, but lacked two of the other egc, sem and sen. This dichotomy was very evident following maximum parsimony (MP) analysis shown in figure $3 \mathrm{~B}$, showing $\mathrm{V}-046$ as an island connecting the CC5 and $\mathrm{CC} 8$ isolates. It appeared to be a transitional genotype between the two groups, because it shared the virulence genes of CC5 and CC8, including sek. The MP analysis (figure 3B) showed the genetic distance as measured by additive gain or loss of single virulence genes. Based on MP analysis, USA300 and USA500 isolates were closer relative to each other, but separated from the USA100 and USA800 clones.
The ST8:USA300 isolates were branched off from the ST8:USA500 isolates due the presence of the lukSF-PV genes. There was extensive overlap in the virulence profiles of the USA100 and USA800-like strains associated with CC5.

\section{Discussion}

Human to human transmission of MRSA occurs commonly in hospitals and in people who live in crowded settings. ${ }^{38-40}$ Methicillin-resistant $S$. aureus has also been identified in many small and large animals. ${ }^{6,8,11,26,27}$ However, the identification of human MRSA genotypes in either healthy or diseased animals raises the intriguing possibility of zoonotic and reverse zoonotic transmission of MRSA. Indeed, several reports from Canada and Europe documented the presence of identical PFGE types in animals and their handlers or owners. ${ }^{12,15,19,23,24,41-45}$

In our study, the proportion of $S$. aureus and MRSA in all CPS was $12 \%$ and $5 \%$, respectively. However, the proportion 

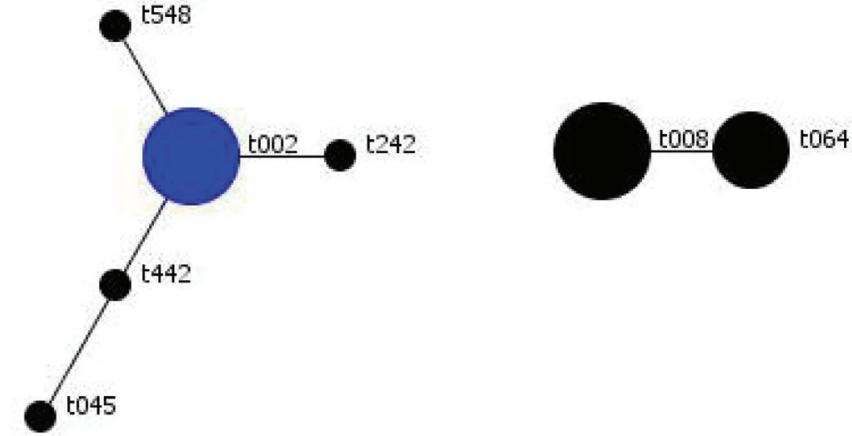

Figure 2. A snapshot of the spa type-based clonal relatedness of the 24 MRSA isolates based on BURP analysis. Each dot represents a unique spa type, and the blue dot represents the group founder with the highest founder score which is a spaCC. Shown here is the spa clonal complex 002 with its founder and two spa types t008 and t064 with no founder. The lines joining the spa types do not represent the genetic distance between them.

of MRSA among S. aureus isolates recovered was rather high $(36.4 \%)$. In cats, dogs, horses, and pigs, the four frequently studied species for MRSA prevalence, we found the rate of MRSA in CPS was highest for pigs (50\%), followed by horses $(42 \%)$, cats $(12 \%)$, and dogs $(2 \%)$. Interestingly, however, the proportion of MRSA in S. aureus in dogs (37\%) was higher than cats $(32 \%)$. Pigs had a higher proportion of MRSA compared to dogs and cats (table 1). Two recent studies have provided surveillance data for the rate of prevalence of $S$. aureus and MRSA in healthy and inflammatory skin diseased (ISD) cats and dogs. ${ }^{26,27}$ The cat study showed that $20 \%$ of healthy and $29 \%$ of the diseased cats were culture-positive for S. aureus, whereas only $2 \%$ and $4 \%$, respectively, were positive for MRSA. ${ }^{26}$ A similar study showed that nearly the same percentages of healthy (12\%) and the ISD (10\%) dogs carried S. aureus. Within this population, $1.7 \%$ of ISD dogs had MRSA compared to $0 \%$ in the healthy group. ${ }^{27}$ Our study, which looked only into CPS isolates of the animals with wounds or infections, found MRSA at the rate of $2 \%$ in dogs and $4 \%$ in cats. Also, the percent of CPS that were S. aureus in our study was higher for dogs but smaller in cats compared to the findings of Abraham et $\mathrm{al}^{26}$ and Griffeth et al. ${ }^{27}$ In a study that focused on the rate of prevalence of $S$. aureus and MRSA carriage in non-healthcare workers, healthcare workers, and veterinary healthcare workers and their symptomfree healthy household pets, Kottler et $\mathrm{al}^{28}$ showed that $\sim 8 \%$ of dogs carried methicillin-sensitive-SA (MSSA) compared to $\sim 6 \%$ of cats. The percent of MRSA were $3.3 \%$ for dogs and $\sim 4 \%$ for cats. One of the conclusions from that study was that "animals were less likely to be colonized with MSSA than people, and there was no statistical difference in the proportion of MRSA among S. aureus isolated from people or pets." ${ }^{28}$ This study also did not find statistical difference in the proportion of dogs compared to cats colonized with MSSA or MRSA. These differences in the rates of colonization or infections from $S$. aureus and MRSA are likely to be influenced by geographical region, patient population, source of the clinical samples (nasal vs. rectal in case of colonization), and degree of exposure to healthcare environments.

In our study, different USA genotypes were found to be associated with dogs and cats as compared to horses. The dog and cat isolates predominantly belonged to the USA 100 type (71\%; spa type:t002, $60 \%$ and t548, 17\%) whereas $100 \%$ of the horse isolates ${ }^{46}$ were in USA500 type (t064, 80\% and t190, 20\%). Indeed, USA100 and USA 800 were the two most common PFGE types reported in humans colonized with MRSA during the study period of 2001 to 2004 in the United States. ${ }^{47,48}$ A higher proportion of USA100 PFGE types in cats and dogs in our study is notable because this clone was the most frequently identified PFGE type in invasive MRSA infections in a population-based surveillance study in the United States. ${ }^{49}$ The identification of four cases of ST8:USA300 genotypes in cats, dogs, and pigs was also significant. To the best of our knowledge this is the first report of a skin and soft tissue infection in a pig due to a USA300 genotype.

Weese et $\mathrm{al}^{20,46}$ have also reported from studies done in Canada that MRSA clones similar to USA100 were found to colonize and/or infect small animals, and whereas MRSA clones similar to USA500 were prevalent in equine isolates. This pattern of two different MRSA lineages affecting two different animal populations has also been observed in veterinary personnel who worked either with small or large animals in the United Kingdom and Ireland. ${ }^{17}$ MRSA clones isolated from veterinary personnel who worked with small animals were similar to USA100 (ST5, SCCmec type II), whereas MRSA isolated from veterinary personnel who worked with large animals were represented by clones similar to USA500 (ST8, SCCmec type IV). ${ }^{22,46}$ It would be interesting to identify which staphylococcal genetic factors favor such host specificity for infection in small versus large animals. Most of the horse MRSA isolates in our study were resistant to tetracycline and sulfamethoxazole (SXT). A higher percent of resistance to these antimicrobials has also been reported in MRSA isolates recovered from horses in Canada. ${ }^{15,46}$ Indeed, SXT and tetracycline are commonly used antibiotics in horses while enrofloxacin and erythromycin are not. Our virulence profile data of equine isolates suggests the presence of three clusters. Cluster $\mathrm{C}$ included a single isolate which harbored seb, sek and three genes of the egc in addition to the four adhesion genes. Cluster D which was mainly distinguished from the cluster $\mathrm{C}$ and $\mathrm{E}$ due to the presence of PVL genes and lack of seb and egc. One of the isolates in this cluster harbored sea. The observation of multiple virulence profiles within a clonal complex in equine isolates suggests either the gain or loss of those genes in USA500 PFGE types.

The recovery of both nosocomial (USA100 and USA500) and CA-MRSA (USA300) associated genotypes in animal isolates in our study suggests a high likelihood of interspecies transmission. Indeed, other studies have shown indistinguishable MRSA strains isolated from humans and animals..$^{17,19,20,45}$ 


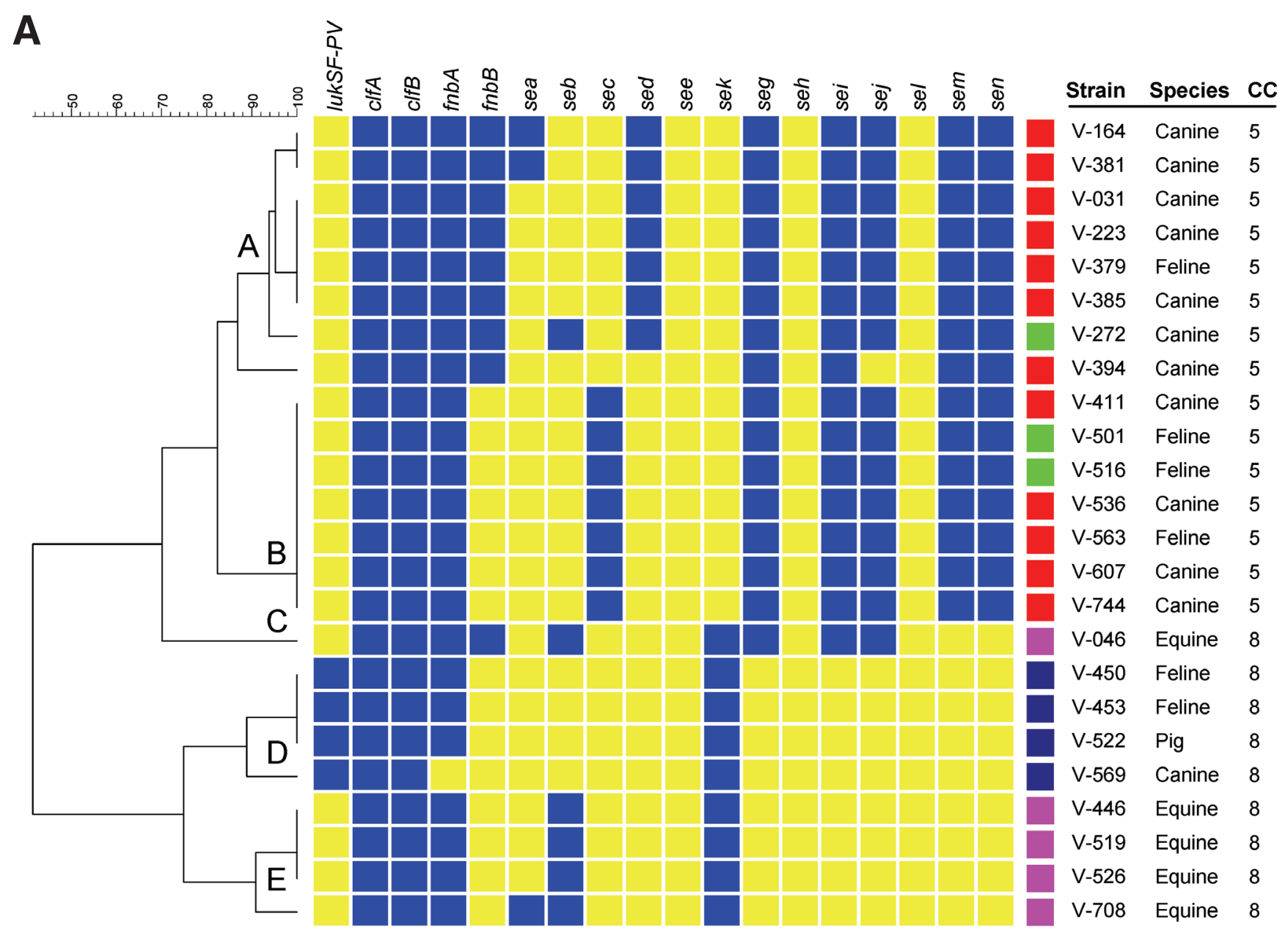

B

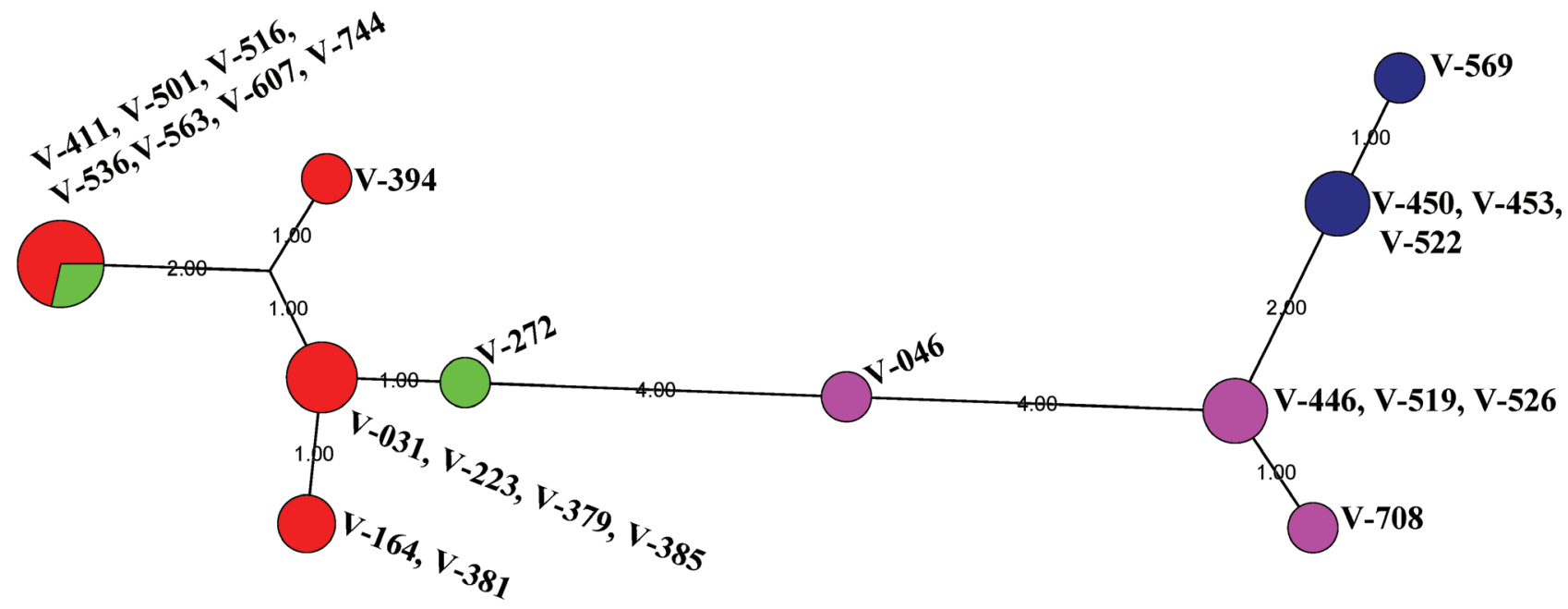

Figure 3. Results and analysis of the virulence gene profile PCR assay. (A) The dendrogram was generated based on the presence/absence of virulence genes. The royal blue boxes indicate the presence and yellow boxes the absence of the corresponding virulence genes. Four virulence groups (clusters A-E) were identified among the strains based on $>85 \%$ similarity. The colored boxes to the right of the virulence gene data correspond to the color scheme in figure 1, where the isolates were grouped based on their USA types. The far right column (CC) refers to the clonal complex of the particular strain. (B) Maximum parsimony analysis of virulence gene profile results. The size of the circle and colored fractions within are proportional to the number of isolates of a particular USA type that have the specific virulence genotype. The length of the lines (and corresponding numbers) separating genotype circles represent the number of virulence gene differences between the adjacent groups. 
One could speculate that owners and/or caretakers were the source of the particular MRSA strain(s) which was subsequently transmitted to animals. This would not be too surprising since humans and companion animals are often in close contact with each other (eg, licking, petting, grooming, lap sitting). This study was not designed to determine whether infected animals could serve as reservoirs for colonization or infection to humans and other animals; however, it is reasonable to assume that a MRSA-positive human or animal could be the source of a new infection both in animals and humans. It is also possible that such animals may have acquired MRSA strains from environmental or other nonhuman sources, since $S$. aureus is known to be a hardy pathogen that can survive in hospital fomites for extended periods. ${ }^{50}$ However, more definitive studies need to be done to determine the persistence of MRSA in dogs and cats and their role as potential short- or long-term reservoirs. This is especially relevant for animals that may be carriers of CA-MRSA through contact with MRSA carriers or contaminated inanimate objects. ${ }^{39}$ Panton-Valentine leukocidin-positive CA-MRSA has been a major cause of skin and soft tissue infections in humans lacking traditional risk factors. ${ }^{1,2,3}$ In addition, CA-MRSA has been reported from hospitals in the United States. ${ }^{2}$ Four isolates in this study had the genotypes of CA-MRSA identified in humans (CC8, SCCmec Type IVa, lukSF-PV+, and spa type t008), suggesting transmission from humans to those animal species. Notably the infection of the pig was due to a PVL-positive USA300 isolate which has not been reported to date. Our study also identified six MLST types belonging to two CCs: CC5 and CC8. In order to better understand the dynamics of transmission of MRSA between humans and animals, a simultaneous screening for MRSA colonization and/or contamination should be performed in owners of the animals, immediate environments of animals where they are housed, and veterinary healthcare providers for the affected animals.

The potential for MRSA to become a problematic zoonotic pathogen could dramatically affect the epidemiology of MRSA in humans. Increased awareness of animals serving as a reservoir for MRSA is important for understanding the changing epidemiology of this pathogen. As the prevalence of MRSA in animals continues to rise, there is an inherent risk for new MRSA clones to evolve secondary to horizontal gene transfer and host selection pressure and then spread to human hosts. This is evident from the different virulence gene profiles of USA100 and USA800 strains identified in this study (figure 3A). Thus, the presence of MRSA in animals is a concern not limited only to veterinarians and animal health care workers, but to public health at large. Identification of MRSA carriers in both humans and animals will be important if recurrent MRSA colonization and/or infection is identified in animals. The possibility of an increase in zoonotic MRSA and its implications for public health warrants further investigation. Furthermore, because the direction of transmission of MRSA between animals and humans is poorly understood, long-term studies tracking carriage status of animals and their human contacts should be conducted. Collaboration between veterinary and human healthcare workers will be necessary to help control the spread of this pathogen between humans and our companion and foodproduction animals.

\section{Acknowledgements}

The authors would like to thank the medical technology staff of the Clinical Microbiology Section of Marshfield Labs for their technical assistance, and Marshfield Clinic Research Foundation for providing summer internships to YL and EB in SKS lab. The Marshfield Clinic Research Foundation's Office of Scientific Writing and Publication provided assistance with this manuscript. The views presented in this manuscript do not necessarily reflect those of the US Food and Drug Administration.

\section{References}

1. Gordon RJ, Lowy FD. Pathogenesis of methicillin-resistant Staphylococcus aureus infection. Clin Infect Dis 2008; 46 Suppl 5:S350-S359.

2. Moran GJ, Krishnadasan A, Gorwitz RJ, Fosheim GE, McDougal LK, Carey R, Talan DA; EMERGEncy ID NET Study Group. Methicillin-resistant $S$. aureus infections in the emergency department. N Engl J Med 2006;355:666-674.

3. David MZ, Glikman D, Crawford SE, Peng J, King KJ, Hostetler MA, Boyle-Vavra S, Daum RS. What is communityassociated Methicillin-resistant Staphylococcus aureus? J Infect Dis 2008;197:1235-1243.

4. McDougal LK, Steward CD, Killgore GE, Chaitram JM, McAllister SK, Tenover FC. Pulsed-field gel electrophoresis typing of oxacillin-resistant Staphylococcus aureus isolates from the United States: establishing a national database. J Clin Microbiol 2003;41:5113-5120.

5. McDougal LK, Wenming Z, Patel JB, Tenover FC. Characterization of two new community-associated oxacillin resistant Staphylococcus aureus pulsed-field types consisting of US isolates that carry SCCmec IV and Panton-Valentine leukocidin genes. Abstr. $104^{\text {th }}$ General Meeting American Society of Microbiology, New Orleans, LA. 2004.

6. Devriese LA, Hommez J. Epidemiology of methicillin-resistant Staphylococcus aureus in dairy herds. Res Vet Sci 1975; 19:23-27.

7. Cuny C, Strommenger B, Witte W, Stanek C. Clusters of infections in horses with MRSA ST1, ST254, and ST398 in a veterinary hospital. Microb Drug Resist 2008;14:307-310.

8. Duquette RA, Nuttall TJ. Methicillin-resistant Staphylococcus aureus in dogs and cats: an emerging problem? J Small Anim Pract 2004;45:591-597.

9. Weese JS. Methicillin-resistant Staphylococcus aureus: an emerging pathogen in small animals. J Am Anim Hosp Assoc 2005;41:150-157.

10. Khanna T, Friendship R, Dewey C, Weese JS. Methicillin resistant Staphylococcus aureus colonization in pigs and pig farmers. Vet Microbiol 2008;128:298303.

11. Loeffler A, Boag AK, Sung J, Lindsay JA, Guardabassi L, Dalsgaard A, Smith H, Stevens KB, Lloyd DH. Prevalence of methicillin-resistant Staphylococcus aureus among staff and pets in a small animal referral hospital in the UK. J Antimicrob Chemother 2005;56:692-697.

12. Smith TC, Male MJ, Harper AL, Kroeger JS, Tinkler GP, Moritz ED, Capuano AW, Herwaldt LA, Diekema DJ. Methicillin-resistant Staphylococcus aureus (MRSA) strain ST398 is present in midwestern U.S. swine and swine workers. PLoS ONE 2008;4:e4258. 
13. van Duijkeren E, Jansen MD, Flemming SC, de Neeling H, Wagenaar JA, Schoormans AH, van Nes A, Fluit AC. Methicillin-resistant Staphylococcus aureus in pigs with exudative epidermitis. Emerg Infect Dis 2007;13:14081410.

14. Walther B, Wieler LH, Friedrich AW, Hanssen AM, Kohn B, Brunnberg L, Lubke-Becker A. Methicillin-resistant Staphylococcus aureus (MRSA) isolated from small and exotic animals at a university hospital during routine microbiological examinations. Vet Microbiol 2008; 127:171-178.

15. Weese JS, Archambault M, Willey BM, Hearn P, Kreiswirth BN, Said-Salim B, McGeer A, Likhoshvay Y, Prescott JF, Low DE. Methicillin-resistant Staphylococcus aureus in horses and horse personnel, 2000-2002. Emerg Infect Dis 2005; 11:430-435.

16. Malik S, Coombs GW, O'Brien FG, Peng H, Barton MD. Molecular typing of methicillin-resistant staphylococci isolated from cats and dogs. J Antimicrob Chemother 2006;58:428-431.

17. Moodley A, Stegger M, Bagcigil AF, Baptiste KE, Loeffler A, Lloyd DH, Williams NJ, Leonard N, Abbott Y, Skov R, Guardabassi L. spa typing of methicillin-resistant Staphylococcus aureus isolated from domestic animals and veterinary staff in the UK and Ireland. J Antimicrob Chemother 2006;58:1118-1123.

18. Strommenger B, Kehrenberg C, Kettlitz C, Cuny C, Verspohl J, Witte W, Schwarz S. Molecular characterization of methicillin-resistant Staphylococcus aureus strains from pet animals and their relationship to human isolates. J Antimicrob Chemother 2006;57:461465.

19. van Duijkeren E, Wolfhagen MJ, Box AT, Heck ME, Wannet WJ, Fluit AC. Human-to-dog transmission of methicillinresistant Staphylococcus aureus. Emerg Infect Dis 2004; 10:2235-2237.

20. Weese JS, Dick H, Willey BM, McGeer A, Kreiswirth BN, Innis B, Low DE. Suspected transmission of methicillinresistant Staphylococcus aureus between domestic pets and humans in veterinary clinics and in the household. Vet Microbiol 2006;115:148-155.

21. Guinane CM, Sturdevant DE, Herron-Olson L, Otto M, Smyth DS, Villaruz AE, Kapur V, Hartigan PJ, Smyth CJ, Fitzgerald JR. Pathogenomic analysis of the common bovine Staphylococcus aureus clone (ET3): emergence of a virulent subtype with potential risk to public health. J Infect Dis 2008;197:205213.

22. Hanselman BA, Kruth SA, Rousseau J, Low DE, Willey BM, McGeer A, Weese JS. Methicillin-resistant Staphylococcus aureus colonization in veterinary personnel. Emerg Infect Dis 2006;12:1933-1938.

23. Weese JS, Caldwell F, Willey BM, Kreiswirth BN, McGeer A, Rousseau J, Low DE. An outbreak of methicillin-resistant Staphylococcus aureus skin infections resulting from horse to human transmission in a veterinary hospital. Vet Microbiol 2006;114:160-164.

24. Witte W, Strommenger B, Stanek C, Cuny C. Methicillinresistant Staphylococcus aureus ST398 in humans and animals, Central Europe. Emerg Infect Dis 2007;13:255-258.

25. Wulf MW, Sorum M, van Nes A, Skov R, Melchers WJ, Klaassen CH, Voss A. Prevalence of methicillin-resistant Staphylococcus aureus among veterinarians: an international study. Clin Microbiol Infect 2008;14:29-34.

26. Abraham JC, Morris DO, Griffeth GC, Shofer FS, Rankin SC. Surveillance of healthy cats and cats with inflammatory skin disease for colonization of the skin by methicillin-resistant coagulase positive staphylococci and Staphylococcus schleiferi ssp. Schleiferi. Vet Derm 2007;18:252-259.
27. Griffeth GC, Morris DO, Abraham JL, Shofer FS, Rankin SC. Screening of skin carriage of methicillin-resistant coagulasepositive staphylococci and Staphylococcus schleiferi in dogs with healthy and inflamed skin. Vet Derm 2008;19:142-149.

28. Kottler S, Middleton JR, Perry J, Weese JS, Cohn LA. Prevalence of Staphylococcus aureus and methicillin-resistant Staphylococcus aureus carriage in three populations. J Vet Intern Med 2010;24:132-39.

29. Clinical and Laboratory Standards Institute. Performance Standards for Antimicrobial Disk and Dilution Susceptibility Tests for Bacteria Isolated from Animals: Approved Standard - Second Edition. CLSI document M31-A2. Wayne, PA: Clinical and Laboratory Institute; 2002.

30. Brady JM, Stemper ME, Weigel A, Chyou PH, Reed KD, Shukla SK. Sporadic "transitional" community-associated methicillin-resistant Staphylococcus aureus strains from health care facilities in the United States. J Clin Microbiol 2007;45:26542661.

31. Shimizu A, Kawano J, Yamamoto C, Kakutani O, Anzai T, Kamada M. Genetic analysis of equine methicillin-resistant Staphylococcus aureus by pulsed-field gel electrophoresis. J Vet Med Sci 1997;59:935-937.

32. Bannerman TL, Hancock GA, Tenover FC, Miller JM. Pulsedfield gel electrophoresis as a replacement for bacteriophage typing of Staphylococcus aureus. J Clin Microbiol 1995;33:551-555.

33. Enright MC, Day NP, Davies CE, Peacock SJ, Spratt BG. Multilocus sequence typing for characterization of methicillin-resistant and methicillin-susceptible clones of Staphylococcus aureus. J Clin Microbiol 2000;38:1008-1015.

34. Koreen L, Ramaswamy SV, Graviss EA, Naidich S, Musser JM, Kreiswirth BN. spa typing method for discriminating among Staphylococcus aureus isolates: implications for use of a single marker to detect genetic micro- and macrovariation. J Clin Microbiol 2004;42:792-799.

35. Oliveira DC, Tomasz A, de Lencastre H. The evolution of pandemic clones of methicillin-resistant Staphylococcus aureus: identification of two ancestral genetic backgrounds and the associated mec elements. Microb Drug Resist 2001;7:349-361.

36. Mellmann A, Weniger T, Berssenbrügge C, Rothgänger J, Sammeth M, Stoye J, Harmsen D. Based Upon Repeat Pattern (BURP): an algorithm to characterize the long-term evolution of Staphylococcus aureus populations based on spa polymorphisms. BMC Microbiol 2007;7:98.

37. Shukla SK, Karow ME, Brady JM, Stemper ME, Kislow J, Moore N, Wroblewski K, Chyou P, Warshauer DM, Reed KD, Lynfield R and Schwan WR. Virulence Genes and Genotypic Associations in Nasal Carriage, CommunityAssociated Methicillin-Susceptible and Methicillin-Resistant USA400 Staphylococcus aureus. J Clin Microbiol 2010; In press.

38. Hiramatsu K, Cui L, Kuroda M, Ito T. The emergence and evolution of methicillin-resistant Staphylococcus aureus. Trends Microbiol 2001;9:486-493.

39. Proctor RA. Community acquired methicillin resistant Staphylococcus aureus: A Wisconsin perspective. WMJ. 2006;105:40-45.

40. Centers for Disease Control and Prevention (CDC). Methicillinresistant Staphylococcus aureus skin or soft tissue infections in a state prison--Mississippi, 2000. MMWR Morb Mortal Wkly Rep 2001;50:919-922.

41. Van den Eede A, Martens A, Lipinska U, Struelens M, Deplano A, Denis O, Haesebrouck F, Gasthuys F, Hermans K. High occurrence of methicillin-resistant Staphylococcus aureus ST398 in equine nasal samples. Vet Microbiol 2009; 133:138-144. 
42. van Belkum A, Melles DC, Peeters JK, van Leeuwen WB, van Duijkeren E, Huijsdens XW, Spalburg E, de Neeling AJ, Verbrugh HA; Dutch Working Party on Surveillance and Research of MRSA-SOM. Methicillin-resistant and -susceptible Staphylococcus aureus sequence type 398 in pigs and humans. Emerg Infect Dis 2008;14:479-483.

43. van Duijkeren E, Wolfhagen MJ, Heck ME, Wannet WJ. Transmission of a Panton-Valentine leukocidin-positive, methicillin-resistant Staphylococcus aureus strain between humans and a dog. J Clin Microbiol 2005;43:62096211.

44. van Loo I, Huijsdens X, Tiemersma E, de Neeling A, van de Sande-Bruinsma N, Beaujean D, Voss A, Kluytmans J. Emergence of methicillin-resistant Staphylococcus aureus of animal origin in humans. Emerg Infect Dis 2007; 13:1834-1839.

45. Vitale CB, Gross TL, Weese JS. Methicillin-resistant Staphylococcus aureus in cat and owner. Emerg Infect Dis 2006;12:1998-2000.

46. Weese JS, Rousseau J, Traub-Dargatz JL, Willey BM, MCGeer AJ, Low DE. Community-associated methicillin-resistant Staphylococcus aureus in horses and humans who work with horses. J Am Vet Med Assoc 2005;226:580-583.

47. Gorwitz RJ, Kruszon-Moran D, McAllister SK, McQuillan G, McDougal LK, Fosheim GE, Jensen BJ, Killgore G, Tenover FC, Kuehnert MJ. Changes in the prevalence of nasal colonization with Staphylococcus aureus in the United States, 2001-2004. J Infect Dis 2008;197:1226-1234.

48. Tenover FC, McAllister S, Fosheim G, McDougal LK, Carey RB, Limbago B, Lonsway D, Patel JB, Kuehnert MJ, and Gorwitz R. Characterization of Staphylococcus aureus isolates from nasal cultures collected from individuals in the United States in 2001 to 2004. J Clin Microbiol 2008;46:2837-2841.

49. Klevens RM, Morrison MA, Fridkin SK, Reingold A, Petis S, Gershman K, Ray S, Harrison LH, Lynfield R, Dumyati G, Townes JM, Craig AS, Fosheim G, McDougal LK, Tenover FC; Active Bacterial Core Surveillance of the Emerging Infections Program Network. Community-associated methicillin-resistant Staphylococcus aureus and healthcare risk factors. Emerg Infect Dis 2006;12:1991-1993.

50. Huang R, Mehta S, Weed D, Price CS. Methicillin-resistant Staphylococcus aureus survival on hospital fomites. Infect Control Hosp Epidemiol 2006;27:1267-1269.

51. Johnson A, Pylka S, Olsen K, Sreevatsan S, Bender J. Methicillin-resistant Staphylococcus aureus isolated from therapy dogs and handlers within a hospital setting. In: ASMESCMID Conference Proceedings: Methicillin-resistant staphylococci in animals: veterinary and public health implications. September 22-25, 2009. London, England.

52. Umber JK, Bender JB. Pets and antimicrobial resistance. Vet Clin Small Anim 2009;39:279292.

\section{Author Affiliations}

Yihan Lin, BS*; Emily Barker*; Jennifer Kislow, BS*;

Pravin Kaldhone, MS*; Mary E. Stemper, MS\%;

Madhulatha Pantrangi, PhD*; Frances M. Moore, DVMt;

Matthew Hall, MD\$; Thomas R. Fritsche, MD*\#;

Thomas Novicki, PhD广; Steven L. Foley, PhD**;

Sanjay K. Shukla, PhD*

* Molecular Microbiology Laboratory, Marshfield Clinic

Research Foundation, Marshfield, Wisconsin, USA

†Clinical Microbiology, Marshfield Labs, Marshfield,

Wisconsin, USA

Veterinary Pathology, Marshfield Labs, Marshfield, Wisconsin, USA

$\S$ Department of Infectious Disease, Marshfield Clinic, Marshfield, Wisconsin, USA

\#University of Wisconsin, La Crosse, Wisconsin, USA

**Division of Microbiology, National Center for

Toxicological Research, U.S. Food and Drug

Administration, Jefferson, Arkansas, USA 